\title{
Pengembangan rencana induk ruang terbuka hijau berbasis masyarakat Desa Lambang Sari I, II, III Kecamatan Lirik Kabupaten Indragiri Hulu Riau
}

\author{
Sri Wulandari1, Suwondo ${ }^{1}$ \& Gun Faisal ${ }^{(i D}$ *2 \\ ${ }^{1}$ Fakultas Keguruan dan Ilmu Kependidikan, Universitas Riau, Indonesia \\ 2 Fakultas Teknik, Universitas Riau, Indonesia \\ *gunfaisal@eng.unri.ac.id
}

\begin{abstract}
The utilization of green open space (RTH) in Desa Lambang Sari I, II, III, Kecamatan Lirik Kabupaten Indragiri Hulu used for ordinary services, such as gardening, exercising, and interacting, aims to determine its utilization based on activity types, the actor, vegetation types, utilization time, and its contributions on socio-cultural, economic, and environmental aspects, as well as to build collaboration between the community and the government to create an integrated RTH. The methods applied to achieve these goals included (a) Identifying the existing conditions of public RTH to determine its form, type, and function, (b) identifying the RTH utilization patterns including its types, implementation time, actors and forms of management, frequency of utilization, benefits of activity implementation and, (c) identifying the role of the community in the public RTH utilization, and (d) formulating the development of RTH needed by Desa Lambang Sari I, II, III. In the end, a development master plan was created based on the needs of the community, which became the reference for the development of this green open space.
\end{abstract}

Abstrak Pemanfaatan ruang terbuka hijau (RTH) di Desa Lambang Sari I, II, III Kecamatan Lirik Kabupaten Indragiri Hulu hanya berupa pemanfaatan biasa meliputi berkebun, berolahraga, bermain dan berinteraksi. Pemanfaatan ruang terbuka hijau ini bertujuan untuk mengetahui pemanfaatan RTH berdasarkan jenis kegiatan, pelaku, jenis vegetasi dan waktu pemanfaatannya ruang terbuka hijau publik serta kontribusi dalam aspek sosial budaya, ekonomi dan lingkungan. Selain itu, terciptanya kolaborasi antara masyarakat dan pemerintah untuk menciptakan RTH yang terintegrasi. Untuk mencapai tujuan ini dilakukan metode sebagai berikut; (a) Identifikasi kondisi eksisting ruang terbuka hijau publik bertujuan untuk menentukan bentuk, jenis dan fungsi ruang terbuka hijau publik, (b) identifikasi pola pemanfaatan ruang terbuka hijau publik yang terdiri dari jenis ruang terbuka hijau publik, waktu pelaksanaan, pelaku dan bentuk pengelolaan, frekuensi pemanfaatan, manfaat pelaksanaan kegiatan dan, (c) mengidentifikasi peran masyarakat dalam pemanfaatan ruang terbuka hijau publik, serta (d) merumuskan pengembangan ruang terbuka hijau yang dibutuhkan oleh Desa Lambang Sari I, II, III. Pada akhirnya tercipta sebuah rencana induk pengembangan yang berdasarkan kebutuhan masyarakat yang menjadi rujukan pengembangan ruang terbuka hijau ini.

Keywords: green open space; integreted; Lambang Sari Village 123; role of community

\section{¿ OPEN ACCESS}

Citation: Wulandari, S., Suwondo, \& G. Faisal (2021). Pengembangan rencana induk ruang terbuka hijau berbasis masyarakat Desa Lambang Sari I, II, III Kecamatan Lirik Kabupaten Indragiri Hulu Riau. Riau Journal of Empowerment, 4(1), 11-20. https://doi.org/10.31258/raje.4.1.11-20

Received: 2020-11-22 Revised: 2021-04-14 Accepted: 2021-04-17

Language: Bahasa Indonesia (id)

ISSN 2623-1549 (online), 2654-4520 (print)

(c) 2021 Sri Wulandari, Suwondo \& Gun Faisal. Author(s) retain the copyright of article published in this journal, with first publication rights granted to Riau Journal of Empowerment. The article is licenced under Creative Commons Attribution 4.0 International License. This license permits unrestricted use, distribution, and reproduction in any medium, provided the original author and source are credited. 


\section{PENDAHULUAN}

Pengaturan mengenai Ruang Terbuka Hijau (RTH) Kota telah dijelaskan dalam Peraturan Menteri dalam Negeri No 1 Tahun 2007 tentang Ruang Terbuka Hijau Kawasan Perkotaan (RTHKP) dimana Ruang Terbuka Hijau Kawasan Perkotaan yang selanjutnya disingkat RTHKP adalah bagian dari ruang terbuka suatu kawasan perkotaan yang diisi oleh tumbuhan dan tanaman guna mendukung manfaat ekologi, sosial, budaya, ekonomi dan estetika. RTH memiliki peran penting bagi suatu perkotaan, hal ini dapat dilihat bahwa kewajiban ketersediaan Ruang Terbuka Hijau di suatu wilayah kota paling sedikit 30\% dari luas wilayah, RTH publik sebesar 20\% dan sisanya RTH privat (Sholihah \& Sabarisman, 2018). Pengelolaan RTH dapat dilakukan dengan perencanaan yang baik, dengan lingkup mencakup perencanaan pemanfaatan RTH, pelaksanaan, pengawasan, pengendalian, dan evaluasi.

Ruang terbuka hijau ditujukan sebagai strategi perencanaan kota yang berguna untuk memperbaiki dampak lingkungan negatif dari kepadatan tinggi (Xue et al., 2017). Keberadaan RTH juga menjadi bagian dari lanskap perkotaan dan kelestarian kota. Ruang terbuka meningkatkan kualitas lingkungan, kualitas hidup, dan mempromosikan interaksi sosial dan inklusi (Rojas et al., 2016). Secara teoritis yang dimaksud dengan ruang terbuka adalah ruang yang berfungsi sebagai wadah (container) untuk kehidupan manusia, baik secara individu maupun berkelompok, serta wadah makhluk lainnya untuk hidup dan berkembang secara berkelanjutan (Santoso et al., 2019).

Desa Lambang Sari I, II, III adalah salah satu desa yang di bangun oleh Perusahaan Pertambangan Minyak Bumi PT. Stanvac Indonesia Lirik (PTSI) Lirik Kabupaten Indragiri Hulu. Desa ini berdiri sejak tahun 1958 yang dahulunya merupakan komplek perumahan karyawan perusahaan pertambangan. Adapun jumlah penduduk Desa Lambang Sari I, II, III sebanyak 1.171 Jiwa dengan jumlah presentase laki-laki (49\%) dan perempuan (51\%), selain itu berdasarkan usia kategori berusia dibawah 15 tahun sebesar (21\%), berusia diantara 15-65 tahun $(71 \%)$, dan diatas 65 tahun $(7 \%)$.

Masyarakat merupakan objek dan subjek mestinya berperan dalam memberikan masukan bagi daerahnya sehingga aktivitas dapat terpenuhi dengan baik sesuai dengan keinginan bersama. Mewujudkan lingkungan yang baik dan merasakan manfaat dari RTH sebagai sarana rekreasi dan juga pusat kesejukan kota karena adanya RTH yang rapi dan asri. Partisipasi masyarakat dalam pembentukan RTH sangat penting dengan pendekatan bottom up dan topdown yang menjadikan masyarakat sebagai basis perencanaan.

Pemanfaatan RTH publik di Desa Lambang Sari I, II, III diantaranya adalah berkebun, berolahraga, bermain, berinteraksi, bercocok tanam, dan lain sebagainya. Fenomena yang terjadi pada saat ini adalah aktivitas RTH publik di Desa Lambang Sari I, II, III masih ada yang kurang diperhatikan sehingga dibutuhkan pengembangan berbasis masyarakat serta peran pemerintah dalam melakukan kontrol. Peran masyarakat sangatlah penting guna untuk mempertahankan keberadaan dan pengendalian dalam pemanfaatan RTH publik sesuai fungsinya.

Partisipasi masyarakat merupakan bentuk peran serta dalam mewujudkan pembangunan, diharapkan adanya hubungan timbal balik sehingga masyarakat berperan aktif. Masyarakat Desa Lambang Sari I, II, III dan pemerintah Kabupaten Indragiri Hulu bersama-sama diuntungkan dalam rangka memajukan pembangunan yang yang berwawasan lingkungan. Peran serta masyarakat dalam pengelolaan Ruang Terbuka Hijau merupakan salah satu faktor pentingnya guna mengurangi potensi timbulnya konflik kepentingan dalam pemanfaatan 
ruang. Melihat fungsi dari ruang terbuka hijau, maka pengelolaannya tidak dapat dipisahkan dari masyarakat. Hal inilah sangat perlu keterlibatan dan peran serta masyarakat dalam merencanakan, membangun bersama pengelolaan RTH dan bersinergi dengan perguruan tinggi dan pemerintah kelurahan.

Wulandari et al.

\section{3}

\section{METODE PENERAPAN}

\section{Langkah-Langkah Kegiatan}

Metode dalam pengabdian ini yaitu metode observasi, diskusi dan pendampingan perencanaan secara langsung bersama. Observasi dilakukan untuk mendata permasalahan yang ada di kawasan. Diskusi dilakukan adalah upaya memperoleh informasi kebutuhan pengguna. Metode analisis yang digunakan adalah Synchronic Reading untuk menemukan sinkronisasi fakta empirik yang dijumpai di lapangan (Darjosanjoto, 2006). Pendampingan dilakukan dalam proses perencanaan dan pengembangan RTH Desa Lambang Sari I, II, III Kecamatan Lirik Kabupaten Indragiri Hulu. Adapun bagan tahapan kegiatan sebagai berikut.

a. Observasi lapangan, dilakukan pencatatan data mengenai kondisi eksisting untuk mendapatkan gambaran dan informasi detail dilokasi.

b. Wawancara, dilakukan untuk mendapatkan informasi mengenai permasalahan dan usulan dari masyarakat terhadap RTH Desa Lambang Sari, I, II, III.

c. Dokumentasi, dilakukan untuk mengumpulkan data visual berupa foto, video dan gambar.

d. Studi dokumen, dilakukan untuk mempelajari kajian teori pustaka, studi literatur, peraturan atau kebijakan pemerintah.

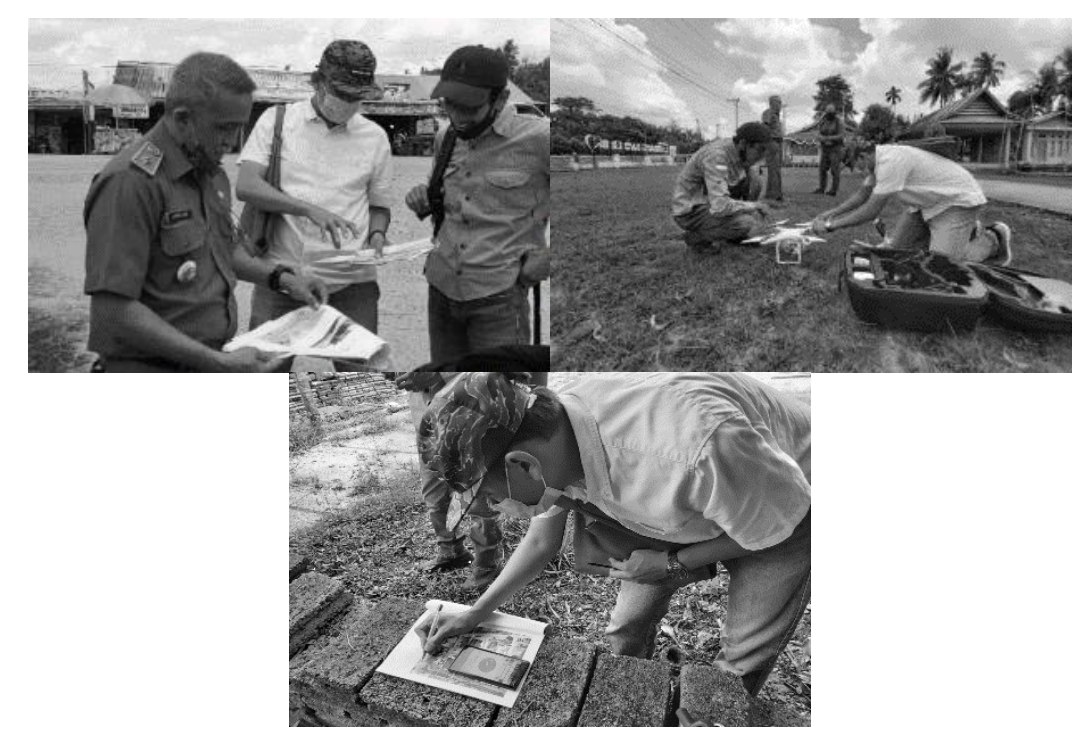

Gambar 1. Observasi lapangan, pengumpulan data, diskusi dan pendampingan masyarakat

\section{Teknik Penyelesaian Masalah}

Adapun Teknik Penyelesaian Masalah disajikan sebagai berikut:

a. Perumusan masalah

Tahap awal menentukan objek penataan yaitu lahan milik desa Lambang Sari I, II, III. Melihat potensi dan masalah yang akan diselesaikan pada perencanaan Ruang terbuka Hijau. 
b. Survei dan investigasi data dan informasi kawasan

Untuk memperoleh data perlu melakukan investigasi informasi secara langsung pada lapangan. Pengambilan data dengan melakukan observasi menelusuri kawasan menggunakan Drone. Kemudian melakukan pemotretan fenomena fisik dan kegiatan, melakukan pengukuran objek.

c. Analisis potensi dan permasalahan data

Data di interpertasikan sehingga perancang memahami kondisi kawasan. Maka dapat menyusun potensi dan hambatan permasalahan pada kawasan. Untuk mendapatkan fakta empirik maka perlu melakukan cara analisis synchronic reading.

d. Pengembangan konsep

Pengembangan konsep dari kriteria-kriteria dan potensi yang dapat dikembangkan serta permasalahan yang harus diselesaikan maka hal tersebut dirumuskan dengan diskusi secara bottom-up dengan masyarakat.

e. Usulan konsep

Usulan konsep desain dievaluasi dengan melihat apakah usulan tersebut sudah sesuai tujuan solusi (keinginan pengguna), kriteria, dan mampu menyelesaikan permasalahan.

f. Visualisasi desain

Setelah usulan konsep sudah dievaluasi dan adanya revisi, maka desain divisualisasikan baik dalam dua dimensi maupun tiga dimensi berupa siteplan RTH dan animasi visual. Tahap terakhir kegiatan pengabdian ini adalah tahap penulisan laporan.

\section{Alat Ukur Ketercapaian}

a. Meningkatkan dan menumbuhkan kesadaran masyarakat pentingnya keberadaaan Ruang Terbuka Hijau.

b. Terbentuknya interaksi sosial dalam sebuah kawasan, tetapi juga berperan penting dalam menjaga sistem ekologis lingkungan secara keseluruhan di samping mendukung terbentuknya unsur estetika dalam lingkungan.

c. Menghasilkan sebuah konsep/desain pengembangan RTH di Desa Lambang Sari, I, II, III Kecamatan Lirik kabupaten Indragiri Hulu.

\section{HASIL DAN KETERCAPAIAN SASARAN}

\section{Gambaran Umum Masyarakat Sasaran}

Desa Lambang Sari I, II, III adalah salah satu Desa yang di bangun oleh Perusahaan Pertambangan Minyak Bumi PT. Stanvac Indonesia Lirik (PTSI) Lirik. Desa ini berdiri sejak tahun 1958 yang dahulunya merupakan komplek perumahan karyawan perusahaan pertambangan tersebut. Adapun jumlah penduduk Desa Lambang Sari I, II, III sebanyak 1.171 Jiwa dengan jumlah presentase laki-laki (49\%) dan perempuan (51\%), selain itu berdasarkan usia kategori berusia dibawah 15 tahun sebesar (21\%), berusia diantara 15-65 tahun (71\%), dan berusia diatas 65 tahun (7\%).

Sebagai desa yang letaknya di pinggiran area lintas jalan maka sangat diperlukan RTH Sehingga kedepannya bisa menjadi salah satu generator penggerak perekonomian masyarakat setempat. Namun kondisinya pada saat ini memiliki keterbatasan infrastruktur pendukung kegiatan aktivitas tersebut, yaitu tarebatasnya fasilitas berupa sarana dan prasana ataupun lansekap RTH. Fasilitas lansekap RTH merupakan salah satu infrastruktur yang dibutuhkan guna memperlancar dan meningkatkan citra kawasan yang saat ini sudah memiliki potensi 
alam berupa waduk/danau dan lingkungan alam pepohonan dan area pertanian/ perkebunan. Potensi alam ini nantinya bisa di kolaborasikan menjadi satu-kesatuan atraksi wisata yang bisa di jual guna meningkatakan nilai tambah kawasan. Ruang Terbuka Hijau merupakan elemen penting karena membentuk lingkungan yang ada nyaman dan sehat (Mbarep dan Herdiansyah,

Wulandari et al.

Fenomena yang terjadi pada saat ini adalah aktivitas pemanfaatan RTH publik di Desa Lambang Sari I, II, III masih kurang dimanfaatkan sehingga dibutuhkan partisipasi masyarakat dan pemerintah untuk melakukan pengembangan. Oleh karena itu peran masyarakat sangatlah penting guna untuk mempertahankan keberadaan dan pengendalian dalam pemanfaatan ruang terbuka hijau publik sesuai fungsinya. Pengembangan RTH strategis adalah kegiatan pembangunan RTH yang mengutamakan lingkungan, kerjasama, memberikan kesempatan kerja serta tanggung jawab (Lestari et al., 2014).

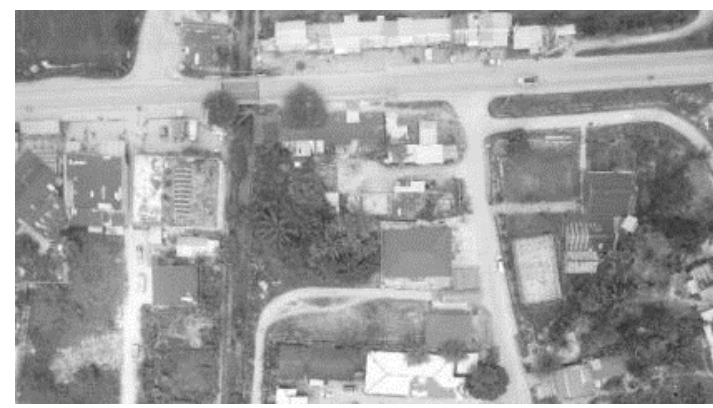

Gambar 2. Kondisi tapak area kegiatan RTH

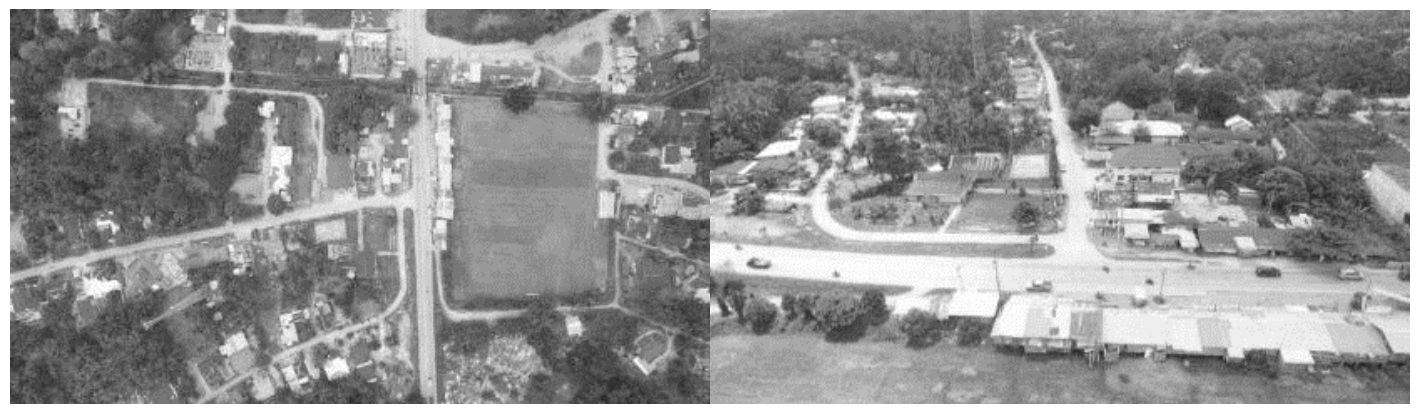

(a)

(b)

Gambar 3. Kondisi sekitar Tapak Area pengembangan RTH (a) Top View (b) Perspektif View

\section{Potensi Pengembangan (Pemberdayaan) Masyarakat}

Pengembangan RTH publik dan privat sampai saat ini masih terbatas pada pengelolaan lingkungan, kemampuan masyarakat untuk turut serta aktif dalam program pengelolaan lingkungan sangat kecil (Fadhillah, 2016). Kondisi ini berdampak pada fungsi RTH belum dirasakan oleh masyarakat dan berdampak pada aspek pemeliharaan yang kurang diperhatikan. Ruang terbuka hijau lebih memberikan kesadaran akan kesehatan manusia bagi masyarakat dan terbukti dengan dominasi kegiatan program terkait kesehatan manusia (Dewi, et al., 2018). Disamping itu sebagai ruang publik dan sarana sosial masyarakat, secara tidak langsung memiliki fungsi untuk meningkatkan kualitas sosial masyarakat berupa kesehatan masyarakat, hiburan dan penyalur komunikasi. Responsibilitas masyarakat dibutuhkan utuk membangun lingkungan RTH yang lebih luas pada prinsipnya jika suatu program itu memberikan keuntungan bagi masyarakat, maka responsibiltas akan sangat tinggi. Ada 
beberapa bentuk yang dapat diterapkan dalam meningkatkan responsibilitas masyarakat melalui RTH yaitu; budidaya/pembibitan tanaman, mengembangkan RTH berbasis agribisnis, mengembangkan ruang publik dengan fuungsi pendidikan dan hiburan. Dengan adanya RTH pada Desa Lambang sari I, II, III diharapkan meningkatakan nilai tambah kawasan terutama aspek Lingkungan, Ekonomi dan Sosial berkelanjutan.

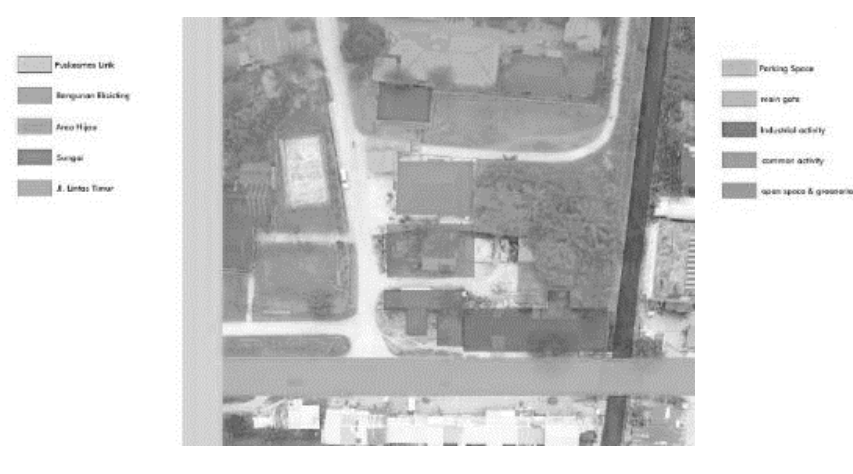

(a)

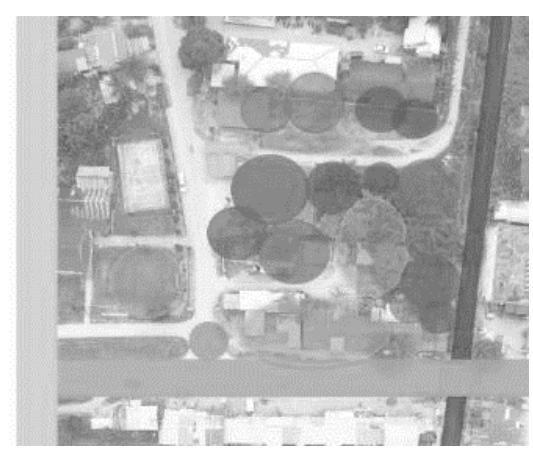

(b)

Gambar 4. (a) Kondisi Existing yang bisa di kembangkan (b) Zoning Pengembangan Ruang Terbuka Hijau

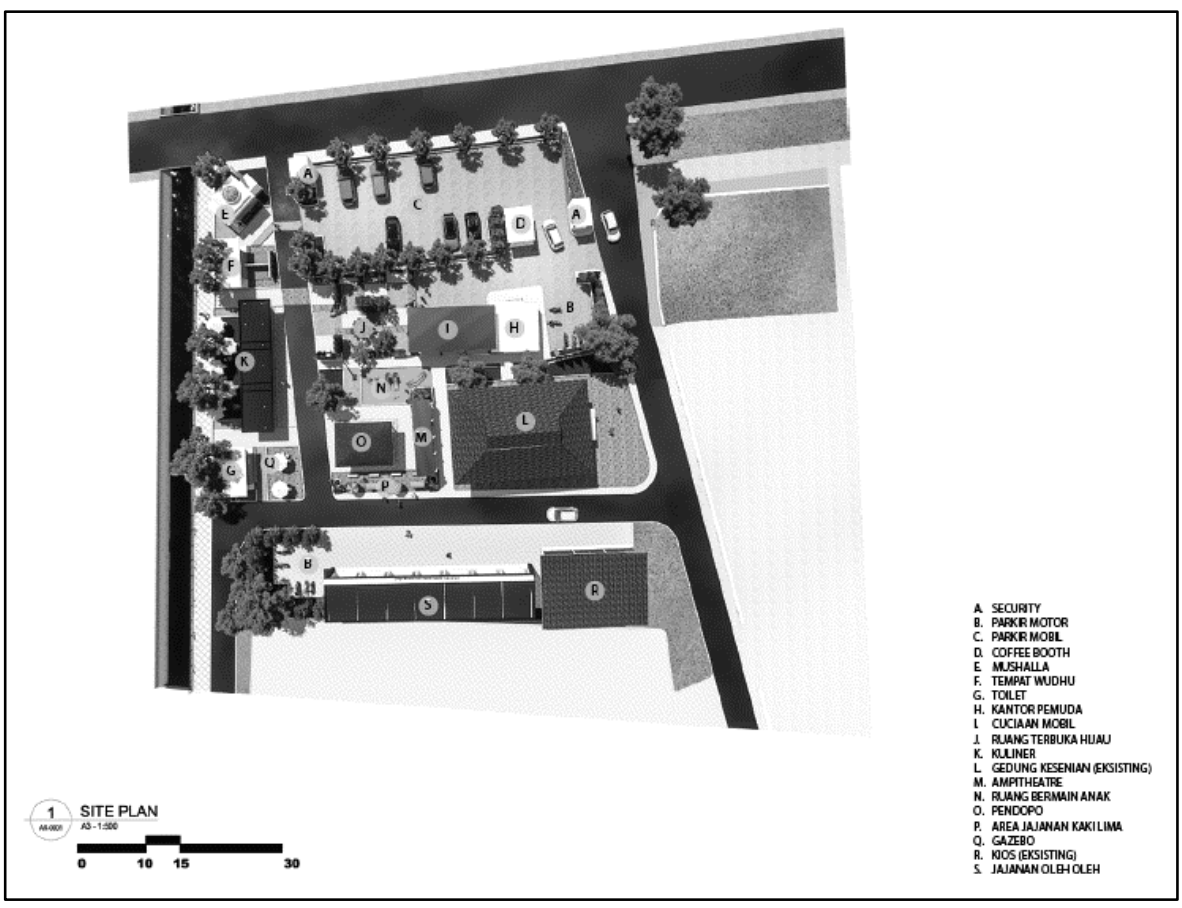

Gambar 5. Site Plan

\section{Peran Serta Masyarakat Dalam Menunjang Keberhasilan Pengembangan RTH}

Beberapa faktor penyebab tidak tersedianya RTH adalah fasilitas yang tidak memadai untuk membantu pekerjaan di otoritas perencanaan (masyarakat), kurangnya dana, tidak tersedianya informasi ruang hijau dan kurangnya pelatihan yang tepat (Olaleye et al., 2013). Dalam upaya menciptakan masterplan RTH ini peran masyarakat sangat penting, hal ini dikarenakan masyarakat sebagai pengguna tentu memiliki keinginan dan kebutuhan yang sesuai dengan apa yang mereka harapkan. Diskusi dengan Kepala Desa dan Perangkat Desa lainya, seperti Karang Taruna dan ibu-ibu penggerak PKK sebagai penggunan RTH ini sangat penting. 
Kegiatan ini merupakan bagian awal dari identifikasi permasayalahan dan kebutuhan lapangan. Selanjutnya dilakukang FGD (Focus Group Discussion) melalui video conference (Zoom Meeting) dikarenakan kondisi pandemic sehingga membatasi pertemuan tatap muka. Pada saat FGD ini, masyarakat wajib memberikan masukan agar hasil akhir dapat optimal.

Wulandari et al.

\section{7} Masukan dari user (masyarakat desa) ditampung utnuk perbaikan masterplan RTH ini. Selanjutnya mengundang masyarakat, dalam hal ini Kepala Desa dalam diskusi akhir kegiatan pembuatan masterplan ini, agar masyarakat merasa bahwa ini merupakan upaya mereka dan milik mereka, kegiatan ini diakhiri dengan penyerahan hasil masterplan RTH ini secara simbolis.

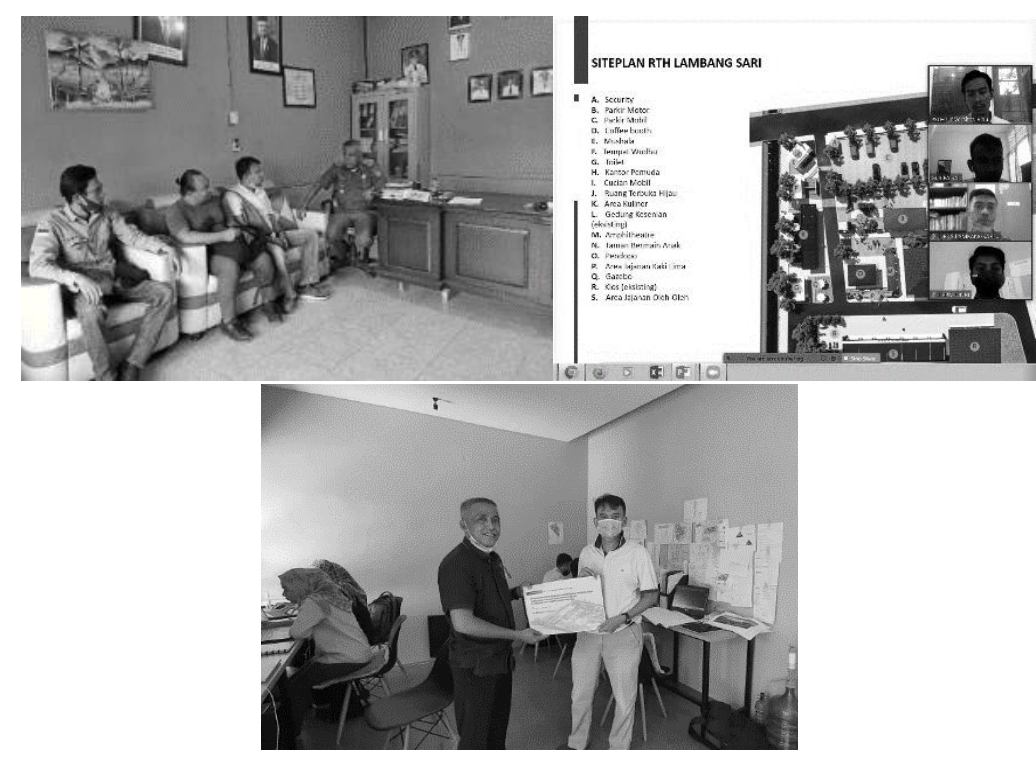

Gambar 6. Diskusi Penyamaan Persepsi, Pengambilan Masukan dan FGD Bersama Masyarakat serta Penyerahan Hasil Pendampingan kepada Kepala Desa.

\section{Solusi Pengembangan (Pemberdayaan) Masyarakat}

Mengidentifikasi karakteristik pengembangan ruang terbuka hijau pada kawasan permukiman di desa Lambang Sari I, II, III kecamatan Lirik kabupaten Indragiri Hulu sehingga diketahui struktur ruang terbuka hijau yang berkembang diwilayah tersebut. Adapun kendala dalam pelaksanaan penataan RTH adalah masalah pendanaan, pengawasan \& penegakan hukum, serta komitmen pemerintah kabupatern Indragiri hulu. Kurangnya partisipasi masyarakat dan pihak swasta juga menjadi kendala yang harus ditingkatkan oleh pemerintah kabupaten Indragiri hulu. Solusi yang dapat dilakukan adalah dengan cara meningkatkan kesadaran masyarakat akan pentingnya RTH yang bisa mendukung proses perencanaan dan pembangunan daerah. 


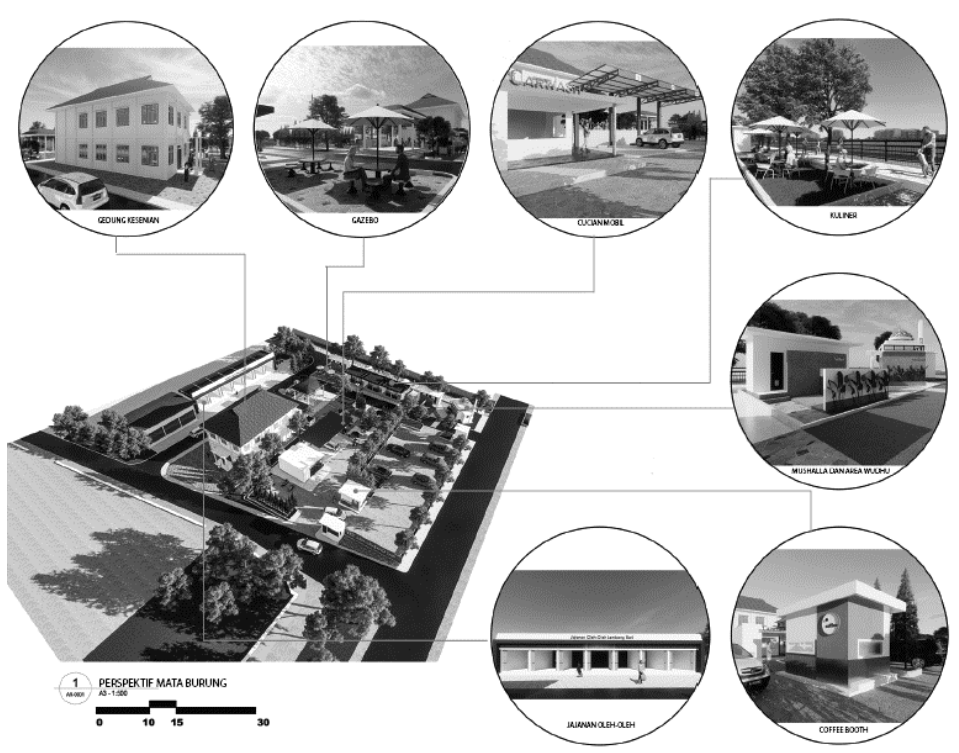

Gambar 7. Rencana Pengembangan Ruang Terbuka Hijau

Adapun fasilitas yang akan dikembangkan pada RTH ini adalah sebagai berikut: Pos Keamanan; Halte; Taman bermain Anak; Parkir; Fasilitas komersil masyarakat; Area terbuka; Ampiteater; dan Lampu outdor.

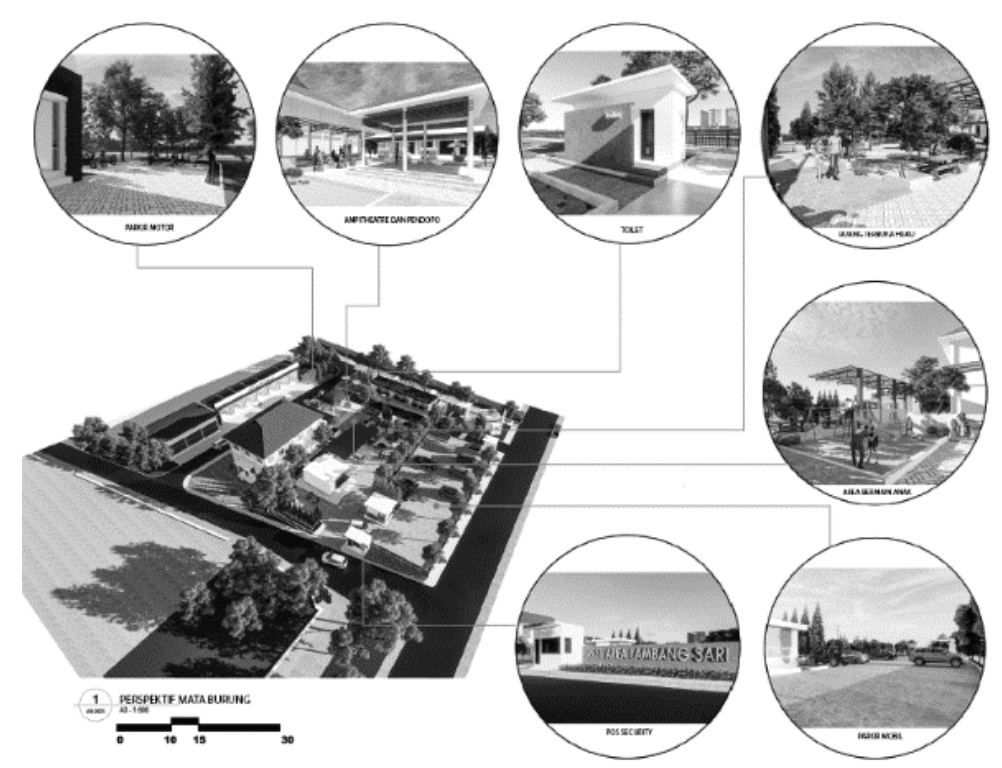

Gambar 8. Rencana Fasilitas Pengembangan Ruang Terbuka Hijau

\section{Tingkat Ketercapaian Sasaran Program}

Adapun ketercapaian sasaran program sebagai berikut; (a) Teridentifikasinya kondisi eksisting ruang terbuka hijau publik bertujuan untuk mengetahui bentuk, jenis dan fungsi ruang terbuka hijau publik, (b) terindetifikasinya pola pemanfaatan ruang terbuka hijau publik terdiri dari jenis RTH publik, waktu pelaksanaan, pelaku dan bentuk pengelolaan, frekuensi pemanfaatan, manfaat pelaksanaan aktivitas dan, (c) teridentifkasinya peran masyarakat dalam memanfaatkan ruang terbuka hijau publik, (d) terumuskannya pengembangan ruang terbuka hijau yang dibutuhkan Desa Lambang Sari I, II, III. Analisis pemanfaatan ruang terbuka hijau 
publik ini bertujuan untuk mengetahui apa saja pemanfaatan ruang terbuka hijau yang dilakukan di desa Lambang Sari I, II, III berdasarkan jenis aktivitas, pelaku, jenis vegetasi dan waktu pemanfaatan ruang terbuka hijau publik serta kontribusi yang diberikan dilihat dari segi sosial dan budaya, ekonomi dan lingkungan disajikan pada Gambar 9.

Wulandari et al.

\section{9}

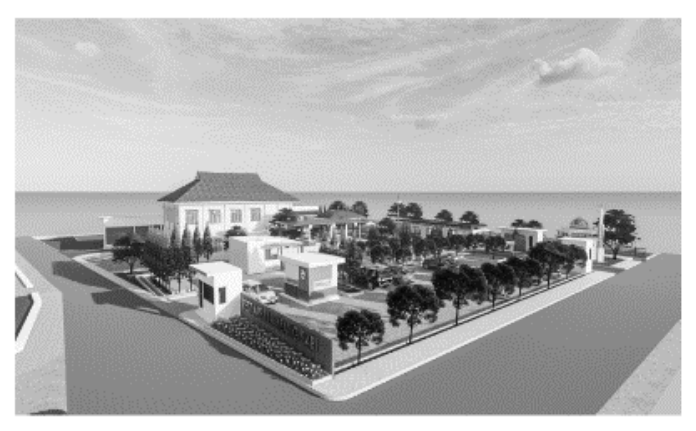

PERSPERTF MATA BURUNC

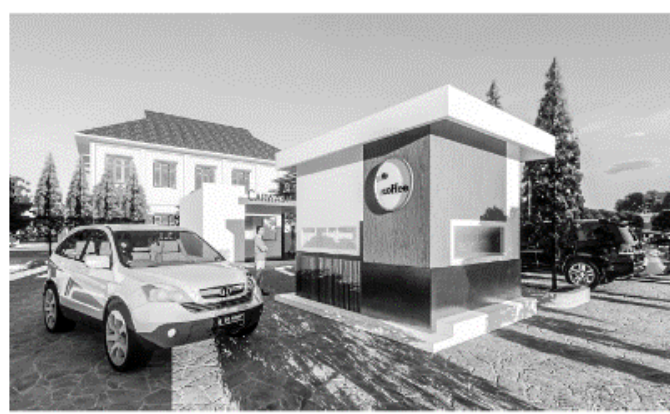

COFEE BOOIH

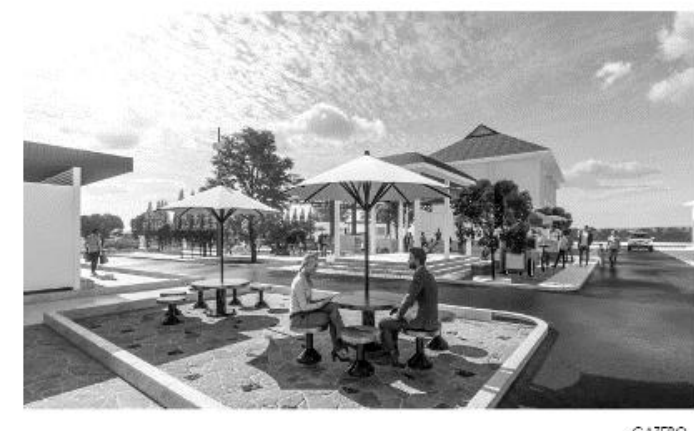

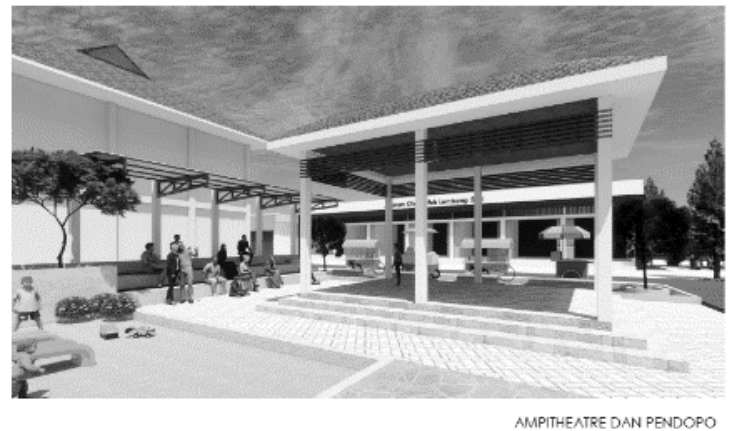

AMPTHENTRE DAN PENDOPO

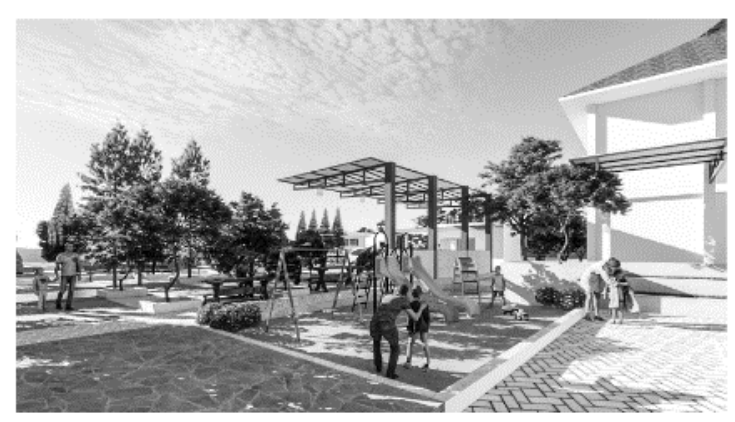

AREA BERMAIN ANAK

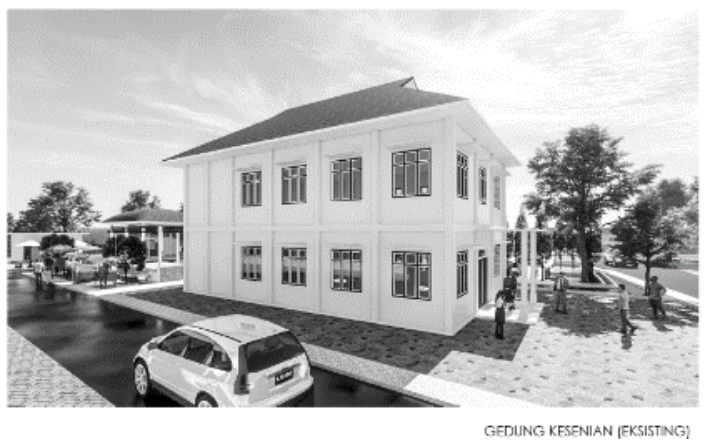

Gambar 9. Pemanfaatan Ruang Terbuka Hijau Desa Lambang Sari I, II, III

\section{KESIMPULAN}

Kesimpulan kegiatan pengabdian kepada masyarakat di Desa Lambang Sari I, II, III Kecamatan Lirik yaitu terumuskannya desain pengembangan ruang terbuka hijau yang dibutuhkan Desa Lambang Sari I, II, III dalam meningkatkan nilai tambah kawasan terutama aspek Lingkungan, Ekonomi dan Sosial berkelanjutan. Rencana induk ruang terbuka ini menghasilkan sebuah rancangan yang memudahkan masyarakat dalam mengembangkan ruang terbuka hijau dan mempermudah melakukan langkah-langkah pemngembangan selanjutnya.

Regulasi yang ada harus diturunkan dalam bentuk rencana aksi dan strategi yang lebih jelas. Pemerintah harus berani menambah anggaran untuk pelaksanaan kebijakan penataan RTH ini. Karena bidang lingkungan selalu membutuhkan banyak dana sementara hasilnya baru bisa dinikmati dalam jangka panjang. Pemerintah harus meningkatkan partisipasi aktif masyarakat dan pihak swasta demi kesuksesan kebijakan ini. Dana pihak swasta seperti CSR bisa 
dimanfaatkan. Dengan pengelolaan yang baik dana yang diperoleh akan sangat membantu pemerintah dalam pelaksanaan RTH, seperti penanaman pohon, pembuatan taman, dan sebagainya.

\section{UCAPAN TERIMA KASIH}

Terima kasih kami ucapkan kepada jajaran perangkat Desa Lambang Sari I, II, III. Selanjutnya ucapan terima kasih kepda LPPM Univeristas Riau atas dukungan yang diberikan. Selain itu Tim dari PSLH LPPM UNRI yang membantu sehingga kegiatan pengabdian ini terlaksana dengan lancar.

\section{Daftar Pustaka}

1. Darjosanjoto, E. T. S. (2006). Penelitian Arsitektur di Bidang Perumahan dan Permukiman. Surabaya: ITS Press.

2. Dewi, O. C., Chairunnisa, I., Hidayat, T., Anggraini, M. And Napitupulu, A. (2018). Green Open Space: Awareness for Health or Sustainability? IOP Conference Series: Earth and Environmental Science, 120, 012014, https://doi.org/10.1088/1755-1315/120/1/012014

3. Fadhillah, I. (2016). Identifikasi Ruang Terbuka Hijau (RTH) Di Kawasan Strategis Kota (KSK) Pusat Kota Sukabumi. Jurnal Online Mahasiswa (Jom) Bidang Perencanaan Wilayah \& Kota, 1(1), 1-13. https://jom.unpak.ac.id/index.php/teknikpwk/article/view/124

4. Lestari, S. P., Noor, I dan Ribawanto, H. (2014). Pengembangan Ruang Terbuka Hijau (RTH) dalam Upaya Mewujudkan Sustainable City (Studi Pada Masterplan Pengembangan RTH Tahun 2012-2032 di Kabupaten Nganjuk). Jurnal Administrasi Publik (JAP), 2(3), 381-387. http://administrasipublik.studentjournal.ub.ac.id/index.php/jap/article/view/394

5. Mbarep, D. P and Herdiansyah, H. (2019). Ecological function of green open space as water infiltration: Study in kalijodo green open space, north jakarta. Journal of Physics: Conference Series, 1381, 012049. https://doi.org/10.1088/1742-6596/1381/1/012049

6. Olaleye, D. O., Ayoade, O. J., and Omisore, E. O. (2013). A Multivariate Analysis of Factors Influencing Green Space Provision in Residential Neighbourhood of Sub-Sarahan African Cities, Journal of Environment and Earth Science, 3(5), 138-146. https://www.iiste.org/Journals/index.php/JEES/article/view/5727

7. Rojas, C., Paez, A., Barbosa, O., \& Carrasco, J. (2016). Accessibility to urban green spaces in Chilean cities using adaptive thresholds. Journal of Transport Geography, 57, 227-240. https://doi.org/10.1016/j.jtrangeo.2016.10.012

8. Santoso, B., Hidayah, R dan Sumardjito. (2019). Pola Pemanfaatan Ruang Terbuka Hijau Pada Perkawasan Perkampungan Plemburan Tegal Ngaglik Sleman. Jurnal jurusan pendidikan teknik sipil dan perencanaan, Inersia, VIII(1), 1-14. https://journal.uny.ac.id/index.php/inersia/article/view/3694

9. Sholihah, I \& Sabarisman, M. (2018). Pemenuhan Kesejahteraan Sosial Melalui Optimalisasi Ruang Terbuka Hijau (RTH) Di Kawasaan Perkotaan Dalam Perspektif Hukum dan Kebijakan. Sosio Informa, 4(01), 297-312. https://doi.org/10.33007/inf.v4i1.949

10. Xue, F., Gou, Z. \& Lau, S. (2017). The green open space development model and associated use behaviors in dense urban settings: Lessons from Hong Kong and Singapore. Urban Des Int, 22, 287-302. https://doi.org/10.1057/s41289-017-0049-5 